\title{
Human toxocariasis - a look at a neglected disease through an epidemiological 'prism'
}

\author{
Ali Rostami ${ }^{\mathrm{a}, 1}$, Guangxu Ma ${ }^{\mathrm{b}, 1}$, Tao Wang ${ }^{\mathrm{b}}$, Anson V. Koehler ${ }^{\mathrm{b}}$, Andreas Hofmann \\ , , Calum N. Macpherson ${ }^{\mathrm{c}}$, Robin B. Gasser ${ }^{\mathrm{b}, *}$ \\ a Infectious Diseases and Tropical Medicine Research Center, Health Research Institute, Babol \\ University of Medical Sciences, Babol, I.R. Iran \\ ${ }^{\mathrm{b}}$ Department of Veterinary Biosciences, Melbourne Veterinary School, The University of Melbourne, \\ Parkville, Victoria, Australia \\ ' School of Graduate Studies, St. George's University, Grenada; School of Veterinary Medicine, St. \\ George's University, Grenada; Windward Islands Research and Education Foundation, Grenada \\ 'Texas Children's Hospital Center for Vaccine Development, and Departments of Pediatrics and \\ Molecular Virology \& Microbiology, National School of Tropical Medicine, Baylor College of \\ Medicine, Houston, Texas, USA
}

\footnotetext{
*Corresponding author.

E-mail address:robinbg@unimelb.edu.au (R.B. Gasser)

${ }^{1}$ joint first authors.
} 


\section{A B S T R A C T}

Toxocariasis, a disease caused by infection with larvae of Toxocara canis, $T$. cati and/or congeners, represents clinical syndromes in humans including visceral and ocular larva migrans, neurotoxocariasis and covert/common toxocariasis. It is reported to be one of the most widespread public health and economically important zoonotic parasitic infections that humans share with dogs, wild canids, including foxes, and possibly other mammals. Humans become infected by accidental ingestion of embryonated Toxocara eggs or larvae from tissues from domestic or wild paratenic hosts. Most infections are asymptomatic, and human disease may go unnoticed, as clinical investigation is often not pursued and/or diagnostic testing not conducted. Sometimes toxocariasis can be associated with complications, such as allergic and/or neurological disorders, possibly including cognitive or developmental delays in children. There is no anti-toxocariasis vaccine, and chemotherapy in humans varies, depending on symptoms and location of larvae, and may include the administration of albendazole or mebendazole, together with anti-inflammatory corticosteroids. Some recent studies indicate that toxocariasis is having an increased, adverse impact on human health in some, particularly underprivileged, tropical and subtropical communities around the world. Although tens of millions of people, especially children, are expected to be exposed to, or infected by, Toxocara species, there is limited precise epidemiological data or information on the relationship between seropositivity and disease (toxocariasis) on a global scale. To gain an improved insight into this area, the present article reviews salient clinical aspects of human toxocariasis and the epidemiology of this disease, with particular reference to seroprevalence, and discusses future research and approaches/measures to understand and prevent/control this socioeconomically important, yet neglected zoonosis.

Keywords:

Toxocara canis

Toxocara cati

Larva migrans

Toxocariasis

Seroprevalence

Epidemiology 


\section{Introduction}

Toxocariasis results from the transmission of Toxocara species from carnivores, including canids and felids, to humans (Dantas-Torres and Otranto, 2014; Macpherson, 2013; Nichols, 1956; Wilder, 1950). Toxocara adults live in the small intestines of wild or domestic definitive hosts. The geographically most widespread and important zoonotic species, $T$. canis, infects a wide variety of canids, including dogs, foxes, wolves, jackals and coyotes, whilst T. cati and T. malaysiensis infect felids (Fisher, 2003; Gibbons et al., 2001; Schnieder et al., 2011). Infected definitive hosts excrete unembryonated Toxocara eggs in faeces, which contaminate the environment and/or the hosts' hair. Under favourable temperature and humidity conditions, eggs embryonate over weeks to months and can remain infective in the environment for months to years (El-Tras et al., 2011; Overgaauw et al., 2009; Roddie et al., 2008).

Toxocara eggs containing infective third-stage larvae (L3s) are often accidentally ingested by humans from contaminated food, water and/or the environment (soil or sand). In the small intestines, L3s emerge from the eggs, migrate through the intestinal wall and then via the circulatory system to organs including liver, lungs, central nervous system and/or musculature; L3s can undergo arrested development within tissues for at least several months (Schnieder et al., 2011). Infective eggs ingested by transport or paratenic hosts, including rodents (mice and rats), lagomorphs (rabbits), ruminants (cattle), suids (swine) or birds (chickens), undergo a similar fate, with L3s migrating to and then arresting in tissues (cf. Strube et al., 2013). If L3-infected tissues from paratenic hosts are food sources for humans and definitive hosts, ingestion can result in infection (Schnieder et al., 2011; Strube et al., 2013). The consumption of infected raw or undercooked ruminant liver has been implicated in human toxocariasis (Salem and Schantz, 1992; Yoshikawa et al., 2008).

Thus, humans are infected via a variety of routes, and it is thought that children usually become infected by accidentally ingesting infective eggs of Toxocara from the environment or, occasionally, by eating invertebrates, such as earthworms, whilst some people become infected by ingesting the tissues of infected vertebrate (paratenic) hosts. Ingested larvae penetrate the intestinal wall, invade various tissues and cause immune and inflammatory responses that can lead to symptoms including fever, headaches, coughing and pain (Pawlowski, 2001; Rubinsky-Elefant, 2010; Taylor et al., 1988). The clinical syndromes of human toxocariasis include: visceral larva migrans (VLM), ocular larva migrans (OLM), neurotoxocariasis (NT) (e.g., eosinophilic meningoencephalitis) and covert toxocariasis (CT) (Finsterer and Auer, 2013; Nicoletti, 2013; Rubinsky-Elefant et al., 2010).

Despite the public health and clinical significance of human toxocariasis, particularly in tropical and subtropical regions of the world and in underprivileged communities in temperate climatic zones (Fialho and Corrêa, 2016; Hotez and Wilkins, 2009; Lee et al., 2014; Macpherson, 2013; Overgaauw, 1997; Rubinsky-Elefant, 2010), considerable knowledge gaps in the epidemiology of this disease exist (Çelik et al., 2013; Cooper, 2008; Holland, 2015; Hotez and Wilkins, 2009; Le et al., 2016; Poulsen et al., 2015; Smith et al., 2009). Recent studies indicate that toxocariasis is neglected, and it is not a notifiable disease (Fu et al., 2014; Hayashi et al., 2005; Won et al., 2008). In some communities, despite the humane reduction or treatment of canids and felids to decrease environmental contamination with infective eggs, the anti-Toxocara serum antibody prevalence in humans can remain high (Fu et al., 2014; Hayashi et al., 2005).

This review examines the clinical features and epidemiology of human toxocariasis, and discusses future research needs and approaches/measures to understand and to prevent/control this important and widespread zoonosis.

\section{Toxocariasis - clinical forms and treatment options}

Of the four main clinical forms of toxocariasis (Fig. 1), although relatively uncommon, VLM is the most advanced form of human toxocariasis, mostly affecting children, being associated with signs such as coughing, wheezing, myalgia and/or cutaneous abnormalities (e.g., exczema, pruritus, rash and/or vasculitis) (Despommier, 2003; Gavignet et al., 2008). In addition, VLM cases can present with lymphadenopathy, hepatitis, myocarditis, nephritis and/or arthritis (Despommier, 2003; Kuenzli et al., 2016; Pawlowski, 2001). Asthma and pulmonary fibrosis can be associated with VLM (Aghaei et al., 2018; Cooper, 2008). Eosinophilia and elevated IgE levels are common. Cerebritis can also occur as a result of 
larval invasion into the central nervous system to produce neurotoxocariasis (NT), although NT can also present as a separate syndrome (see below).

OLM refers to human toxocariasis only affecting the eye. It is relatively uncommon, but mostly reported to occur in children between three and 16 years of age (Despommier, 2003; Pivetti-Pezzi, 2009). Uni-ocular visual impairment might occur, accompanied by chronic endophthalmitis/retinitis and/or posterior/peripheral granulomata (Despommier, 2003). The extent of this impairment is linked to migrating or dead larvae and/or resultant immune reactivity against them as well as location in the eye (Pivetti-Pezzi, 2009). Blindness can result from tractional retinal detachment, vitritis and/or cystoid macular oedema (MartínezPulgarin et al., 2015; Pivetti-Pezzi, 2009).

NT is reported to occur mainly in middle-aged people and less in children (Deshayes et al., 2016). Signs relate to the larval migration in the central nervous system and ensuing meningitis, encephalitis, cerebral vasculitis and/or myelitis, usually relating to relatively nonspecific clinical signs, such as headaches and fever (Caldera et al., 2013; Deshayes et al., 2016; Finsterer and Auer, 2007; Vidal et al., 2003). There has been discussion in the literature about possible associations between cerebral toxocariasis and neurodegenerative disorders, including seizure, schizophrenia, cognitive deficits, idiopathic Parkinson's disease and/or dementia (cf. Çelik et al., 2013; Fan et al., 2015; Finsterer and Auer, 2007). There is particular concern about cognitive or developmental delays in children in socioeconomically disadvantaged communities (Walsh and Haseen, 2012). Some studies suggest that NT might represent a cause of poor school performance and other psychological disturbances in this cohort (Hotez, 2014). Involvement of the peripheral nervous system, reflected in radiculitis, inflammation of cranial nerves and/or skeletal muscles, is rarely recorded in humans (Finsterer and Auer, 2007). In a meta-analysis of published information/data representing 2159 people with epilepsy and 2581 people without epilepsy (Luna et al., 2018), it was shown that seropositivity to Toxocara was significantly associated with epilepsy (odds ratio [OR], $1.69 ; 1.42$ to 2.01$)$.

$\mathrm{CT}$, representing 'common toxocariasis' in adults and 'covert toxocariasis' in children, is challenging to diagnose clinically because of non-specific symptoms (Taylor et al., 1988). Clinical signs, such as weakness, pruritus, rash, pulmonary dysfunction, pulmonary insufficiency and/or abdominal pain can be seen in adults, whereas fever, anorexia, headache, nausea, abdominal pain, vomiting, wheezing, lethargy, sleepiness and behavioural disorders, pulmonary symptoms and/or limb pain, might be observed in children (Walsh and Haseeb, 2014). Eosinophilia and elevated IgE levels are common. There appears to be an association between CT and asthma, although some investigators might place developmental and cognitive delays in this category rather than NT (Hotez, 2014; Li et al., 2014; Mendonça et al., 2012). These clinical characteristics can associate with moderate to high anti-Toxocara serum antibody titres (Pawlowski, 2001; Rubinsky-Elefant et al., 2010; Taylor et al., 1988). A meta-analysis (Aghaei et al., 2018) inferred an increased risk for asthma in children who were seropositive to Toxocara (OR, $1.91 ; 1.47$ to 2.47). Another such analysis (Mohammadzadeh et al., 2018) revealed an increased risk of allergic skin disorders in individuals who were seropositive to Toxocara (OR, $1.75 ; 1.16$ to 2.64 ), with seropositivity being significantly associated with urticaria (OR, $2.97 ; 1.53$ to 5.76$)$ but not with atopy (OR, $1.08 ; 0.55$ to 2.15 ) or eczema (OR, $1.62 ; 0.95$ to 2.78 ).

The chemotherapy of human toxocariasis is challenging; some drugs do not reach and penetrate Toxocara larvae in tissues and their efficacy cannot be rigorously assessed in patients. Nonetheless, anthelmintic treatment is recommended for acute toxocariasis, principally to prevent larvae from reaching the central nervous system (Pawlowski, 2001; Wiśniewska-Ligier et al., 2012). Key chemotherapeutics for toxocariasis and their formulations are given in Table 2. Despite limited efficacy, albendazole and mebendazole are commonly used for oral treatment of VLM (Caumes, 2003), albeit these benzimidazoles are poorly soluble, poorly absorbed and undergo extensive, first-pass metabolism in the liver. Albendazole is preferred due to its distribution (of a metabolite) across distinct tissues compared with mebendazole. These benzimidazoles are poorly soluble, poorly absorbed and undergo extensive first-pass metabolism in the liver. In humans, albendazole is absorbed better than mebendazole (bioavailability of $\leq 2 \%$, following a single oral dose); also, albendazole passes through the blood-brain barrier, and is better tolerated than mebendazole (Othman, 2012). In addition, nonsteroidal antiinflammatory drugs or corticosteroids, such as dexamethasone or prednisolone, can be administered to reduce clinical signs linked to allergic responses to Toxocara antigens 
(Despommier, 2003). However, although treatment with albendazole and steroids may result in a favourable clinical outcome (Barisani-Asenbauer et al., 2001; Martínez-Pulgarin et al., 2015), the efficiency of such treatment of OLM (e.g., following ophthalmologic surgery) is unclear (Despommier, 2003). Although animal experiments (C57BL/6 mice) have indicated promising efficacy of fenbendazole formulations at killing $T$. canis larvae in musculature $(89.5-100 \%)$ and/or brain (66.1\%) (Hrčkova et al., 2007; Leonardi et al., 2009), there is a major need for well-controlled experiments. Liposome-encapsulated and polyethylene glycol (PEG)-conjugated compounds show promise for treatment (Barrera et al., 2010; Horiuchi et al., 2005; Hrčkova and Velebný , 2001; Hrčkova et al., 2007; Moreira et al., 2014), but detailed evaluations are needed. There is also an urgent need for clinical studies in people, particularly children. Although other synthetic chemicals and natural products seem to show larvacidal or larvistatic activity (e.g., linoleylpyrrolidilamide, phenazines, tribendimidine and nitazoxanide; extracts from Chenopodium sp., and Nutridesintox ${ }^{\circledR}$ ), they require extensive future investigation to assess their potential against $T$. canis and $T$. cati.

\section{Diagnosis of infection and disease, and its challenges}

In humans, the diagnosis of Toxocara infection or toxocariasis is usually achieved by serology, occasionally combined with imaging methods to detect granulomata (with encapsulated larvae) in tissues. Methods such as enzyme-linked immunosorbent assays (ELISAs), utilising Toxocara [canis] excretory/secretory (TES) antigens (de Savigny et al., 1979), have been used for seroprevalence studies of Toxocara infection/exposure in humans (Elefant et al., 2016; Jin et al., 2013; Magnaval et al., 1991; Mohamad et al., 2009; Noordin et al., 2005; Peixoto et al., 2011; Roldán et al., 2015; Watthanakulpanich et al., 2008; Table 1). ELISA results can be verified by Western blotting to reduce false-positive results relating to background- or cross-reactivity with other parasites (Moreira et al., 2014). This combined approach is preferable (Moreira et al., 2014), but it is important to emphasise that current Toxocara infection cannot be unambiguously differentiated from past infection or exposure (Holland, 2015; Smith et al., 2009). Clearly, problems exist with cross-reactivity in some serodiagnostic tools, leading to false-positive results, especially in geographic areas where polyparasitism is prevalent (Fillaux and Magnaval, 2013; Moreira et al., 2014). Moreover, it is not possible to unambiguously distinguish between $T$. canis and $T$. cati (or possibly $T$. malayensis) infections using current serological or immunological techniques (cf. Poulsen et al., 2015; Schabussova et al., 2007), such that optimised, species-specific diagnostic tools are required to support future epidemiological investigations.

The sensitivity and specificity of serodiagnostic tests for human toxocariasis depend on the antigens used (e.g., somatic products from $T$. canis larvae, native or recombinant TES products, or either glycan antigens or deglycosylated TES), the isotype of antibodies (e.g., IgG, IgG subclass or IgM) being detected and the extent of optimisation of the assays (Peixoto et al., 2011; Roldán et al., 2015). Thus, numerous ELISAs have been established and evaluated including those listed in Table 1. Assays for the specific detection of IgG3 and IgG2 anti-Toxocara antibodies are reported to achieve increased sensitivity and specificity (Magnaval et al., 1991). By contrast, an IgG4-ELISA, employing recombinant proteins (rTES-120 and rTES-30) was reported to achieve 100\% sensitivity, and an IgG-ELISA using deglycosylated TES is claimed to have $100 \%$ sensitivity and specificity (Mohamad et al., 2009; Roldán et al., 2015). Other recombinant proteins have also been assessed as diagnostic antigen candidates (Anderson et al., 2015; Zhan et al., 2015). Although IgG antibody avidity or eosinophil cationic protein levels can be measured to suggest current or past Toxocara infection (Boldiš et al., 2015; Dziemian et al., 2008; Hübner et al., 2001; Magnaval et al., 2001), each assay needs to be critically evaluated.

Especially for the diagnosis of OLM, specific anti-Toxocara antibody in blood (although false-negative results are common) and vitreous or aqueous humour should be assessed, while the detection of specific antibodies in serum as well as eosinophils in cerebrospinal fluid (CSF) need to be evaluated for the diagnosis of NT (Despommier 2003; Macpherson, 2013). In addition to serology, imaging techniques can assist clinical diagnosis in patients with VLM or OLM; this might involve the use of computed tomography (CT), magnetic resonance-imaging (MRI) and/or ultrasound to scan liver lesions relating to VLM, and fluorescein angiography, optical coherence tomography (OCT), ocular ultrasound and/or CT can also be employed to support OLM diagnosis (Macpherson, 2013; Strube et al., 2013). 
However, better diagnostic algorithms and clinical definitions are needed for both $\mathrm{CT}$ and NT.

In paratenic or accidental hosts, the diagnosis of toxocariasis/Toxocara infection can be achieved by histopathological examination, morphometric assessment of larvae (if detected) and/or the specific detection of larval DNA in/from tissues or body fluid samples by molecular means (Fillaux and Magnaval, 2013; Gasser, 2013). As the results from serological tests alone do not allow for an unequivocal diagnosis of infection (Poulsen et al., 2015; Smith and Noordin, 2006), polymerase chain reaction (PCR)-based tools, using genetic markers in the first (ITS-1) and second (ITS-2) internal transcribed spacers (ITS) of nuclear ribosomal DNA (rDNA) or select mitochondrial (mt) genes, can achieve specific diagnosis (e.g., Gasser, 2006, 2013; Jacobs et al., 1997; Jex et al., 2008; Li et al., 2008; Wickramasinghe et al., 2009), and are employed for epidemiological, population genetic and/or systematic investigations. Importantly, these tools allow Toxocara species to be identified molecularly and can be used to discover "new" species, such as T. malaysiensis (Gibbons et al., 2001; Zhu et al., 1998), whose transmission patterns and zoonotic potential are unknown. Studies demonstrating the specific detection of Toxocara DNA by PCR from cerebrospinal fluid from humans or bronchoalveolar lavage from mice show promise as future complementary diagnostic tools (Caldera et al., 2013; Pinelli et al., 2013).

\section{Epidemiology and global health significance}

Toxocara canis and T. cati have have a worldwide distribution (Fisher, 2003; Lee et al., 2010). Some nation-wide studies of these nematode species in dogs and cats estimated respective prevalences of $6 \cdot 1 \%$ and $4.7 \%$ in Germany (Barutzki et al., 2011), $4.5 \%$ in the Netherlands (Overgaauw et al., 2009), and 1.2\%-3.2\% in Australia (Palmer et al., 2008), with marked prevalences (51-100\%) in puppies and in adult dogs (1-45\%) and cats (3.2-91\%) in some surveys in countries including Portugal, Nigeria, India and China (Dai et al., 2009; Fisher, 2003; Lee et al., 2010; Sowemimo, 2007; Traub et al., 2005; Waap et al., 2014). It appears that there are $>77$ million dogs and 93 million cats in the USA (Gompper, 2013), some of which are expected to a play key role in the dissemination of toxocariasis via the excretion of eggs in faeces into playgrounds, sand pits, gardens, parks and beaches, which represents a substantial risk factor of human infection if eggs survive and then become infective in the environment (Fisher, 2003; Manini et al., 2012).

Humans acquire Toxocara infection(s) by accidentally ingesting infective eggs from contaminated soil, water, fruit or vegetables (e.g., Dubná et al., 2007; Poeppl et al., 2013). Humans may also become infected through direct contact with dogs or cats (Poeppl et al., 2013); embryonated eggs have been detected on the hairs of definitive hosts (El-Tras et al., 2011; Roddie et al., 2008; Overgaauw et al., 2009), although the egg numbers on hair are small (Holland, 2015; Keegan and Holland, 2010). People can also become infected by ingesting larvae present in raw or undercooked meat or organs from paratenic hosts, such as rabbits, ruminants and poultry (cf. Dutra et al., 2014; Salem and Schantz, 1992; Taira et al., 2004; Yoshikawa et al., 2008). The apparent broad geographic distribution of Toxocara and multiple transmission routes indicate that toxocariasis is a common helminth infection in humans (Fig. 2; Appendix Table 1).

\subsection{Recent estimates of the prevalence of Toxocara eggs in public places worldwide}

Although many investigations had indicated that environmental contamination with Toxocara eggs is a major risk factor for human toxocariasis, there was, until recently, no detailed analysis of published information. For this reason, we carried out the first systematic review and meta-analysis to evaluate the global prevalence of Toxocara eggs in public places, including playgrounds, parks and beaches (Fakhri et al., 2018). We identified 109 peer-reviewed studies by searching four public databases (Embase, PubMed, Science Direct and Scopus); in these studies, a total of 42,797 soil samples from 40 countries around the world were tested for the presence of Toxocara eggs using conventional diagnostic methods (usually flotation). The results revealed that $21 \%$ (range: 16-27\%) of public places were contaminated with Toxocara eggs, with the highest level being in the Western Pacific region (mean: 35\%; range: 15-58\%) and the lowest in the North and Central Americas (mean: 13\%; range: $8-23 \%$ ). In other WHO regions, contamination (i.e. prevalence) rates varied from 349\%: Africa (mean: 27\%; range: 11-47\%), South America (mean: 25\%; range: 13-33\%), 
South-East Asia (mean: 21\%; range: 3-49\%), Middle East and North Africa (mean: 18\%; range: $11-24 \%$ ) and Europe (mean: 18\%; range: 14-22\%). Moreover, our findings showed that the extent of contamination in public places was linked to climatic and geographical parameters, being higher in regions with a higher relative humidity and being located at higher longitudes and lower latitudes. Overall, this investigation (Fakhri et al., 2018) showed that public places are frequently heavily contaminated with Toxocara eggs. This finding calls for increased awareness of this risk factor and for measures to prevent the transmission of toxocariasis to humans in public places.

\subsection{Estimates of nation-wide seroprevalence rates in humans}

Over the past 36 years, nation-wide surveys of humans have estimated prevalences of specific anti-Toxocara serum antibodies at $0.7 \%$ in New Zealand, $1.6 \%$ in Japan, $2.4 \%$ in Denmark, $6.3 \%$ in Austria, $7 \%$ in Sweden, $14 \%$ in the USA and $31 \%$ in Ireland, but are $>$ $20 \%$ in some ethnic and socioeconomically disadvantaged groups, $22 \%$ in Iran and $81 \%$ in Nepal (Appendix Table 1). Notably, a seroprevalence of $85 \%$ has been recorded in school children in Manado, Indonesia (Hayashi et al., 2005), and $87 \%$ on the Marshall Islands (Fu et al., 2014). However, there are still limited detailed epidemiological data for most countries around the world.

Although human toxocariasis is expected to be common in underprivileged communities in which there is a close relationship between wild or domestic canids/felids and humans, it has been challenging to evaluate the global impact of this neglected disease (Hotez and Wilkins, 2009; Smith et al., 2009), because of some limitations of available diagnostic tools (see section 3; e.g., Fillaux et al., 2013; Holland, 2015; Moreira et al., 2014). Nonetheless, there is an exemplary, large national survey by Won et al. (2008), who utilised representative samples and a well-defined approach (e.g., sample dilution, immunoassay, and statistical analysis) to obtain seroprevalence data. This investigation revealed an age-adjusted seroprevalence for toxocariasis of 13.9\%; the prevalence in Mexican Americans (10.7\%) and non-Hispanic whites $(12 \%)$ was lower than in non-Hispanic blacks $(21.2 \%)$. These numbers were updated in 2018, to find an overall lower prevalence of $5 \%$ but similarities, in terms of higher prevalence rates among selected at-risk groups, including non-Hispanic blacks and Hispanics, living in poverty (Liu et al., 2018). The authors suggested a link to ethnicity and emphasised that this seroprevalence difference might be an important health education message. Nevertheless, it is still challenging to serologically distinguish infection from exposure to Toxocara (Fisher, 2003; Gasser, 2013; Poulsen et al., 2015), which hinders a better understanding of the epidemiology (e.g., transmission dynamics) of human toxocariasis.

\subsection{Seroprevalence estimates for human toxocariasis worldwide}

There has been a need for investigations to estimate the prevalence of human toxocariasis worldwide to justify investments in prevention programs. In spite of the many epidemiological studies of toxocariasis and Toxocara spp., until recently, there had been no seroprevalence estimates for the general human population at the global, regional or national levels. For this reason, we performed a systematic review and meta-analysis of the literature to estimate the regional and global prevalence of anti-Toxocara serum antibodies in human populations around the world (Rostami et al., 2019); the authors used the term ' $T$ seroprevalence', so as to emphasise that the presence of anti-Toxocara serum antibodies can reflect infection or past exposure.

A systematic search was undertaken using data and information (1980 to 2019) from five public databases (Embase, PubMed, SciELO, Scopus and Web of Science). Random effect model-based meta-analysis was employed to calculate overall the prevalence of antiToxocara serum antibodies in people on a national, regional or global scale. Moreover, we evaluated the impact of socio-demographic, geographical and climatic parameters on seroprevalence, and assessed risk factors for seropositivity. By reviewing 250 studies of 265,327 people from 71 countries in WHO regions, we concluded that almost one fifth $(19 \% ; 1,411,749,590$ individuals) of the world's human population is seropositive to Toxocara. The highest seroprevalence rates were found in Africa (mean: 37.7\%; range: 25.7-50.6\%) and the lowest in the Eastern Mediterranean region (mean: 8.2\%; range: 5.1$12.0 \%)$. Relatively high mean seroprevalence rates were also estimated for the South-East 
Asia region (mean: 34.1\%; range: 8.5-12.8\%), the Western Pacific region (mean: 24.2\%; range: $19.7-26.0 \%$ ) and South American countries (mean: 27.8\%; range: 23.1-32.7\%), and lower rates for North American (mean: 12.8\%; range: 10.0-15.8\%) and European (mean: 10.5\%; range: $8.5-12.8 \%$ ) regions. A country or region with a low human development indices (HDIs), income level, latitude, and high environmental temperature and precipitation was more likely to have a high prevalence of anti-Toxocara serum antibodies in the human population. The findings also indicated that potential risk factors associated with Toxocara seropositivity were male gender; living in rural areas; young age; close contact with dogs, cats or soil; consumption of raw meat; and consumption of untreated drinking water.

The findings of a recent study (Rostami et al., 2019) indicated high levels of infection by or exposure to Toxocara spp. in many countries, which calls for increased attention to human toxocariasis and improved measures to prevent adverse health risks of this disease. The risk predictors identified in this investigation should be considered in the design of human toxocariasis prevention programs. Clearly, epidemiological and serological surveys are needed in countries for which prevalence data are lacking, in order to provide a basis for the implementation of future prevention and/or control programs.

\subsection{Molecular epidemiology of Toxocara species of animals}

Toxocara species have been identified and distinguished according to their morphological characteristics and also their particular host species. Recognised species include T. canis and T. tanuki (from canids), T. cati (felines), T. vajrasthirae (mustelids), $T$. lyncus (caracals), $T$. vitulorum (bovids), T. apodemi and T. mackerrasae (rodents), T. paradoxura and T. sprenti (viverrids), and T. pteropodis (bats) (cf. Bowman, 2014). Traditional taxonomic methods can have limitations for the identification and differentiation of some Toxocara species, especially at the larval and/or egg stages (Chen et al., 2012; Gasser et al., 2013, 2016).

In the late 1990s, it was shown that PCR utilizing sequences of ITS-1 and ITS-2 of rDNA were very useful for the differentiation of Toxocara species. Using ITS-2, Jacobs et al. (1997) successfully distinguished T. canis, T. cati and Toxascaris leonina from each other and from other ascaridoids that might be found in human tissues. Subsequently, PCR-based methods using ITS-1 and ITS-2 were employed to identify and differentiate of Toxocara species that were morphologically very similar or ambiguous (Gibbons et al., 2001; Zhu et al., 1998, 2001). For example, this approach was used to characterize a Toxocara species from cats from Malaysia, that, morphologically, was neither T. canis nor T. cati, and, using molecular methods was shown to represent a distinct species. This species was described and named T. malaysiensis (Gibbons et al., 2001; Zhu et al., 1998). In additional studies, T. malaysiensis was shown to occur in cats in China and Vietnam by molecular characterization using ITS-2 as the genetic marker (Le et al., 2016; Li et al., 2006). Our literature searches of international databases and also of the GenBank databases revealed that T. malaysiensis has not yet been found in countries other than Malaysia, China and Vietnam. In addition to rDNA sequences, some studies have indicated that $\mathrm{mt}$ genes can be useful alternative markers for identification, and systematic and phylogenetic relationship analyses of Toxocara species (e.g., Hu et al., 2004; Hu and Gasser, 2006; Jex et al., 2008; Li et al., 2008; Wickramasinghe et al., 2009). Phylogenetic analyses using ITS-1, ITS-2 and mt gene data sets has shown that $T$. malaysiensis (from cats) was more closely related to $T$. cati (from cats) than to T. canis (from dogs) (Zhu et al., 1998; Le et al., 2016; Li et al., 2008). In addition, Wickramasinghe et al. (2009), using mt DNA sequences, reported that $T$. vitulorum was genetically more similar to $T$. malaysiensis than to $T$. canis and $T$. cati, and Sultan et al. (2015) indicated that $T$. canis and $T$. cati were more closely related to one another than to $T$. vitulorum following a phylogenetic analysis of ITS-1 sequence data. Moreover, in the latter study, T. tanuki from raccoon dogs did not cluster with any other species of Toxocara included. We searched international databases for molecular investigations of Toxocara spp. in different hosts and in soil and found only a small number of studies (Table 2), indicating a major need for comprehensive molecular epidemiological studies of Toxocara species in different host species and in public areas in different geographical regions.

\section{Need for public awareness and intervention programs}

The distribution and seroprevalence estimates for human toxocariasis worldwide raises considerable public health concerns. We believe that community awareness about 
toxocariasis is still inadequate, and that improved education will be critical to enhancing a community's understanding of this disease, and its prevention and control (Fig. 3; Holland, 2015; Ma et al., 2018). Some www-based educational resources, such as the Centers for Disease Control and Prevention (CDC, http://www.cdc.gov) and the American Association of Veterinary Parasitologists (AAVP, http://www.aavp.org/) contain comprehensive information on Toxocara/toxocariasis. Veterinary and medical practitioners need to be responsible for educating pet owners about the medical importance of toxocariasis and about how to minimise the risks of zoonotic transmission (Smith et al., 2009). Importantly, veterinary practitioners are commonly exposed and/or infected by Toxocara due to their occupational contact with small animals (Deutz et al., 2005; Poeppl et al., 2013). In contrast to most veterinary courses in parasitology, especially regarding helminths are rarely, if ever, covered in many curricula provided to medical students; therefore, knowledge about toxocariasis is usually quite limited in the medical profession. Since the need for a differential diagnosis of $T$. canis infection may not be considered in a clinical context, patients who present with pulmonary dysfunction (CT), asthma-like symptoms and/or cognitive deficits (NT) are often are often not tested for the possibility of a parasitic infection. Hygiene, preventing children from ingesting infective Toxocara egg-contaminated soil or faeces from carnivores and avoiding the ingestion of uncooked meat or liver are central to preventing toxocariasis in endemic countries (Fan et al., 2013; Moreira et al., 2014). In addition, although asymptomatic infections are often self-limiting, human toxocariasis cases must be treated to prevent NT and OLM (Othman, 2012).

Furthermore, the relationship among animals, humans and the environment must be kept in mind. Since numerous transmission routes are available to Toxocara species, a One Health approach is central to the prevention and control of human toxocariasis (Fig. 3; Holland, 2015; Ma et al., 2018). Reducing Toxocara infection in definitive host populations needs to be a priority to significantly decrease the number of infective Toxocara eggs in public places (Palmer et al., 2008). In this context, measures to prevent dog fouling have been recommended (Atenstaedt and Jones, 2011).

Nijsse and colleagues (2015) indicated that the removal of faeces and anthelmintic treatment strategies (four times per year) would reduce egg output and resultant environmental contamination. Particularly puppies of $<12$ weeks of age and kittens (Morgan et al., 2013; Nijsse et al., 2014) as well as working/stray dogs and cats should be dewormed with an effective anthelmintic drug (El-Tras et al., 2011; Roddie et al., 2008). Such treatment of pregnant animals is not effective at preventing transplacental transmission or subsequent transmammary transmission (post partum), and thus requires further research efforts (cf. Overgaauw and van Knapen, 2013). Controlling transmission is more challenging when wild animals (e.g., foxes) are involved (Holland, 2015; Morgan et al., 2013).

In endemic settings (such as underprivileged, rural communities in tropical towns or cities with poor sanitation and large stray dog or cat populations), intervention needs to be based on a sound understanding of the epidemiology of toxocariasis, human populations at most risk of infection (e.g., age-groups, socioeconomic status, and rural versus urban), and the cost and feasibility of control and surveillance.

\section{Progress through 'omics and informatics- toward new diagnostic and therapeutic approaches}

The $T$. canis genome project (Zhu et al., 2015) represented a major step towards an improved understanding of the molecular biology of the parasite as well as host-parasite relationships, and might support work to develop novel intervention and diagnostic methods (Gasser et al., 2016). The draft genome is $317 \mathrm{Mb}$ in size and was predicted to encode more than 18,500 genes; $78.4 \%$ of these genes could be annotated, and 5406 (29.1\%) were inferred to have homologues in known biological (KEGG) pathways (Gasser et al., 2016; Zhu et al., 2015). Specifically, 870 ES proteins (including proteases, cell adhesion molecules, lectins, SCP/TAPS proteins, and mucins) were predicted to be involved in host invasion and in parasite-host 'cross-talk', such as immune evasion and/or immune modulation; 458 kinases, 408 phosphatases and 127 GTPases were predicted to have important roles in embryonic, larval development and reproduction; and some of the 156 GPCRs, 268 ion channel proteins and 530 transporters might be drug targets. Additionally, intestine-, stage-, and genderenriched molecules/pathways were defined, indicating essential involvement in survival, development and/or reproductive processes (Gasser et al., 2016; Zhu et al., 2015). 
Utilising these genomic and transcriptomic resources (Gasser et al., 2016; Zhu et al., 2015), we explored the transcription profiles of small RNAs in adult $T$. canis (see Ma et al., 2016). The results suggested that miRNAs $T c$-miR-6090 and $T c$-miR-2305 are involved in embryonic and larval development as well as reproduction in T. canis, and that Tc-miR-100, $T c$-miR-34 and Tc-let-7-5p appear to relate to host-parasite interactions. Other miRNAs, including $T c$-miR-5126, $T c$-miR-2861 and $T c$-miR-2881 might be anthelmintic targets and/or link to drug resistance. Such molecular investigations are now starting to enhance our understanding of molecular processes in T. canis, and should provide a foundation for investigations of the parasite's developmental biology, host-parasite cross-talk and disease processes; such studies might also help discovery new intervention and diagnostic approaches (cf. Britton et al., 2015; Hoy et al., 2014; Manzano-Román and Siles-Lucas, 2012).

\section{Prospects for immunoprotection}

There is an increasing interest in vaccines against zoonotic parasitic diseases. However, for many such diseases, protective immunity is often 'blocked' by a parasite's ability to inhibit and/or evade the host immune system (McSorley and Maizels, 2012). For Toxocara species, immune evasion is mediated by surface-coat and excretory/secretory (ES) molecules (Maizels, 2013), which might be vaccine targets for protective type 2-like immune responses (Długosz et al., 2015; Loukas and Maizels, 2000). TES components, originally explored by Maizels et al. (1984), include the C-type lectins TES-32 and -70 and glycosylated mucins which represent a surface-coat of the larval stage (Długosz et al., 2015; Gems and Maizels, 1996; Kennedy et al., 1987; Loukas et al., 1999, 2000; Loukas and Maizels, 2000; Maizels, 2000). Recently, based on analyses of the genome and transcriptomes of T. canis (see Zhu et al., 2015), it was suggested that a vast array of proteases, adhesion molecules, SCP/TAPS proteins and lectins play roles in the host-parasite 'cross-talk' (cf. Gasser et al., 2016).

The host immune response to Toxocara includes a dominant $\mathrm{CD} 4^{+} \mathrm{T}$-helper type 2 cell (Th2) activity, eosinophilia and production of specific antibodies (Del Prete et al., 1991; Maizels, 2013). TES antigens drive the production of type 2 cytokines (e.g., interleukin-4, IL-5, -10, and -13) from peripheral T-cells in exposed individuals, resulting in eosinophilia, enhanced cytokine expression and the production of IgE antibodies (Del Prete et al., 1991; Maizels, 2013; Mazur-Melewska et al., 2016). These factors might contribute to airway hypersensitivity, linking chronic Toxocara infection to allergic diseases, such as asthma and allergic rhinitis (Cooper, 2008; Maizels, 2013; Yariktas et al., 2007). Interestingly, respiratory signs, such as wheezing, in people (particularly children) can be associated with VLM and CT due to pulmonary migration of Toxocara larvae (e.g., Mendonça et al., 2012; Taylor et al., 1988). Whether children develop asthma later in life is unclear, but there is a possibility that they might be protected from atopic asthma as a result of an immunoregulatory response induced by infection (Cooper, 2008; Yariktas et al., 2007). Although many parasitic helminths can induce immunoregulatory cell populations (e.g., regulatory $T$ cells and alternative-activated macrophages) (Hewitson et al., 2009), it is possible that $T$. canis has evolved to be more immunogenic in accidental hosts, including humans. Nevertheless, some anti-inflammatory effects can be mediated by TES, resulting in, for example, an inhibition of Toll-like receptor signalling and nitric oxide production (Hewitson et al., 2009).

Immunomodulation is a characteristic of Toxocara infections. For example, increased protective pro-inflammatory cytokines (IFN-gamma, IL-6 and IL-13) and anti-inflammatory cytokine (IL-10) can be detected in sera from Toxocara-infected children (Nagy et al., 2012), and macrophages from infected mice produce more IL-10/TGF- $\beta$ and less IL-12/TNF compared with uninfected-control mice (Kuroda et al., 2001). There are various mechanisms contributing to the activation and suppression of immune responses. Firstly, the surface-coat shed by the worm enables migrating larvae to escape from eosinophils that 'stick' to their surface, thus neutralising antibody-dependent elimination (Fattah et al., 1986). Secondly, TES antigens (Th2-stimulator) can also modulate systemic and local immune responses (Maizels, 2013). For example, C-type lectins, particularly TES-32 and TES-70, have marked homology to low affinity $\operatorname{IgE}$ and macrophage mannose receptors in mammals (Loukas et al., 1999), capable of targeting host pathways involved in innate immunity (Hewitson et al., 2009). Additionally, extracellular vesicles (exosomes) might also represent other means of Toxocara being able to modulate immune responses, as such vesicles have been shown to 
transfer ES antigens and non-coding RNAs to host cells (Buck et al., 2014; Quintana etal., 2015). However, this new area should be explored in detail. An improved understanding of specific immune responses and modulatory mechanisms during toxocariasis, and defining immunogenic molecules, could assist significantly in developing an anti-Toxocara vaccine.

\section{Conclusions and future focus}

Toxocariasis is a neglected disease which affects millions of people, pets and stray companion animals around the world. Comprehensive meta-analyses of published seroprevalence and environmental studies suggest that exposure to Toxocara is common, particularly in children who live in subtropical/tropical and underprivileged regions of the world. Improved techniques (immunological, genetic and/or imaging) are needed for the diagnosis of the main clinical forms of toxocariasis (VLM, OLM, CT and/or NT), and need to be accessible to the estimated 750 million people who are at the highest risk of infection and who survive below the World Bank poverty level. There is a clear need to better understand the pathogenesis and impact of CT and NT in people, particularly in disadvantaged community settings; these two clinical conditions might be linked to major causes of pulmonary dysfunction and cognitive delays, respectively, but there are major knowledge gaps, and there are no formal research projects on this topic.

It is possible that the geographic distribution of T. canis, and possibly other species, is expanding as a consequence of increased human and animal mobility, together with the effects of climatic alterations, such as global warming. The human population has doubled in the last 50 years, and, today, more than half of the world's human population live in urban areas. The population of dogs and cats has also grown substantially (Gompper, 2013), increasing the density of these definitive hosts. Much of this growth and concentration has occurred in cities in the tropics and subtropics, and means that without specific prevention and control programs, the prevalence and socioeconomic impact of toxocariasis is likely to increase.

There is a clear need for a better understanding of the molecular epidemiology and ecology of Toxocara/toxocariasis (Gasser, 2013; Ma et al., 2018). Future work might focus on the use of improved molecular tools for specific parasite identification and genetic analysis and for the accurate diagnosis of current infection in people. It would be particularly important to explore, in detail, the zoonotic importance of $T$. cati and whether $T$. malaysiensis and/or whether other congeners other than $T$. canis and $T$. cati also play a significant role in human toxocariasis. Highly sensitive and specific molecular technologies could help establish what role these other ascaridoids play in the epidemiology of toxocariasis, to reveal the true extent and, thus, the public health significance of Toxocara, and would likely underpin new and improved management strategies for the prevention, treatment and control of toxocariasis. Developing an effective ovicidal anthelmintic against Toxocara eggs and/or a vaccine to protect young canids and felids, or people, against toxocariasis, which have long been goals of the scientific community, would enhance the likelihood of controlling this neglected zoonotic disease. It is also hoped that progress in the areas of genomics, transcriptomics, proteomics and bioinformatics and recently established molecular resources will enable the discovery of new intervention targets against $T$. canis and its congeners.

\section{Acknowledgements}

RBG's research program is supported by funds from the Australian Research Council; the National Health and Medical Research Council of Australia; Melbourne Water Corporation; and Yourgene. The authors of this article acknowledge all published works in the field. The authors thank the anonymous reviewers for constructive reports on the submitted manuscript. 


\section{References}

Aghaei, S., Riahi, S.M., Rostami, A., Mohammadzadeh, I., Javanian, M., Tohidi, E., Foroutan, M., Esmaeili Dooki, M., 2018. Toxocara spp. infection and risk of childhood asthma: A systematic review and metaanalysis. Acta Trop. 182, 298-304.

Anderson, J.P., Rascoe, L.N., Levert, K., Chastain, H.M., Reed, M.S., Rivera, H.N., McAuliffe, I., Zhan, B., Wiegand, R.E., Hotez, P.J., Wilkins, P.P., Pohl, J., Handali, S., 2015. Development of a luminex bead based assay for diagnosis of toxocariasis using recombinant antigens Tc-CTL-1 and Tc-TES-26. PLoS Negl. Trop. Dis. 9, e0004168.

Atenstaedt, R.L., Jones, S., 2011. Interventions to prevent dog fouling: a systematic review of the evidence. Public Health 125, 90-92.

Barisani-Asenbauer, T., Maca, S.M., Hauff, W., Kaminski, S.L., Domanovits, H., Theyer, I., Auer, H., 2001. Treatment of ocular toxocariasis with albendazole. J. Ocul. Pharmacol. Ther. 17, 287-294.

Barrera, M.G., Leonardi, D., Bolmaro, R.E., Echenique, C.G., Olivieri, A.C., Salomon, C.J., Lamas, M.C., 2010. In vivo evaluation of albendazole microspheres for the treatment of Toxocara canis larva migrans. Eur. J. Pharm. 75, 451-454.

Barutzki, D., Schaper, R., 2011. Results of parasitological examinations of faecal samples from cats and dogs in Germany between 2003 and 2010. Parasitol. Res. 109, S45-S60.

Boldiš, V., Ondriska, F., Špitalská, E., Reiterová, K., 2015. Immunodiagnostic approaches for the detection of human toxocarosis. Exp. Parasitol. 159, 252-258.

Britton, C., Winter, A.D., Marks, N.D., Gu, H., McNeilly, T.N., Gillan, V., Devaney, E., 2015. Application of small RNA technology for improved control of parasitic helminths. Vet. Parasitol. 212, 47-53.

Buck, A.H., Coakley, G., Simbari, F., McSorley, H.J., Quintana, J.F., Le Bihan, T., Kumar, S., Abreu-Goodger, C., Lear, M., Harcus, Y., Ceroni, A., Babayan, S.A., Blaxter, M., Ivens, A., Maizels, R.M., 2014. Exosomes secreted by nematode parasites transfer small RNAs to mammalian cells and modulate innate immunity. Nat. Commun. 5, 5488.

Caldera, F., Burlone, M.E., Genchi, C., Pirisi, M., Bartoli, E., 2013. Toxocara encephalitis presenting with autonomous nervous system involvement. Infection 41, 691-694.

Caumes, E., 2003. Treatment of cutaneous larva migrans and Toxocara infection. Fundam. Clin. Pharmacol. 17, 213-216.

Çelik, T., Kaplan, Y., Ataş, E., Öztuna, D., Berilgen, S., 2013. Toxocara seroprevalence in patients with idiopathic Parkinson's disease: chance association or coincidence? Biomed. Res. Int. 2013, 685196.

Chen, J., Zhou, D.-H., Nisbet, A.J., Xu, M.-J., Huang, S.-Y., Li, M.-W., Wang, C.-R., Zhu, X.-Q., 2012. Advances in molecular identification, taxonomy, genetic variation and diagnosis of Toxocara spp. Infect. Genet. Evol. 12, 1344-1348.

Choobineh, M., Mikaeili, F., Sadjjadi, S., Ebrahimi, S., Iranmanesh, S., 2019. Molecular characterization of Toxocara spp. eggs isolated from public parks and playgrounds in Shiraz, Iran. J. Helminthol. 93, 306-312.

Cooper, P.J., 2008. Toxocara canis infection: an important and neglected environmental risk factor for asthma? Clin. Exp. Allergy 38, 551-553.

Dai, R.S., Li, Z.Y., Li, F., Liu, D.X., Liu, W., Liu, G.H., He, S.W., Tan, M.Y., Lin, R.Q., Liu, Y., Zhu, X.Q., 2009. Severe infection of adult dogs with helminths in Hunan Province, China poses significant public health concerns. Vet. Parasitol. 160, 348-350.

Dantas-Torres, F., Otranto, D., 2014. Dogs, cats, parasites, and humans in Brazil: opening the black box. Parasit. Vectors 7, 22.

Del Prete, G.F., De Carli, M., Mastromauro, C., Biagiotti, R., Macchia, D., Falagiani, P., Ricci, M., Romagnani, S., 1991. Purified protein derivative of Mycobacterium tuberculosis and excretory-secretory antigen(s) of Toxocara canis expand in vitro human T cells with stable and opposite (type $1 \mathrm{~T}$ helper or type $2 \mathrm{~T}$ helper) profile of cytokine production. J. Clin. Invest. 88, 346-350.

Deshayes, S., Bonhomme, J., Blanchardière, A., 2016. Neurotoxocariasis: a systematic literature review. Infection $44,565-574$.

Despommier, D., 2003. Toxocariasis: clinical aspects, epidemiology, medical ecology, and molecular aspects. Clin. Microbiol. Rev. 16, 265-272.

Deutz, A., Fuchs, K., Auer, H., Kerbl, U., Aspöck, H., Köfer, J., 2005. Toxocara-infestations in Austria: a study on the risk of infection of farmers, slaughterhouse staff, hunters and veterinarians. Parasitol. Res. 97, 390394.

Długosz, E., Wasyl, K., Klockiewicz, M., Wiśniewski, M., 2015. Toxocara canis mucins among other excretorysecretory antigens induce in vitro secretion of cytokines by mouse splenocytes. Parasitol. Res. 114, 33653371.

Dubná, S., Langrová, I., Jankovská, I., Vadlejch, J., Pekár, S., Nápravník, J., Fechtner, J., 2007. Contamination of soil with Toxocara eggs in urban (Prague) and rural areas in the Czech Republic. Vet. Parasitol. 144, 81-86.

Dutra, G.F., Pinto, N.S., de Avila, L.F., Dutra, P.C., Telmo, Pde L., Rodrigues, L.H., Silva, A.M., Scaini, C.J., 2014. Risk of infection by the consumption of liver of chickens inoculated with low doses of Toxocara canis eggs. Vet. Parasitol. 203, 87-90.

Dziemian, E., Zarnowska, H., Kołodziej-Sobocińska, M., Machnicka, B., 2008. Determination of the relative avidity of the specific IgG antibodies in human toxocariasis. Parasite Immunol. 30, 187-190.

Elefant, G.R., Roldán, W.H., Seeböck, A., Kosma, P., 2016. Evaluation of a di-O-methylated glycan as a potential antigenic target for the serodiagnosis of human toxocariasis. Parasite Immunol. 38, 236-243.

El-Tras, W.F., Holt, H.R., Tayel, A.A., 2011. Risk of Toxocara canis eggs in stray and domestic dog hair in Egypt. Vet. Parasitol. 178, 319-323.

Fahrion, A.S., Schnyder, M., Wichert, B., Deplazes, P., 2011. Toxocara eggs shed by dogs and cats and their molecular and morphometric species-specific identification: is the finding of $T$. cati eggs shed by dogs of epidemiological relevance? Vet. Parasitol. 177, 186-189.

Fan, C.K., Holland, C.V., Loxton, K., Barghouth, U., 2015. Cerebral toxocariasis: silent progression to 
neurodegenerative disorders? Clin. Microbiol. Rev. 28, 663-686.

Fan, C.K., Liao, C.W., Cheng, Y.C., 2013. Factors affecting disease manifestation of toxocarosis in humans: genetics and environment. Vet. Parasitol. 193, 342-352.

Fakhri, Y., Gasser, R.B., Rostami, A., Fan, C.K., Ghasemi, S.M., Javanian, M., Bayani, M., Armoon, B., Moradi, B., 2018. Toxocara eggs in public places worldwide - A systematic review and meta-analysis. Environ. Pollut. 242, 1467-1475.

Fattah, D.I., Maizels, R.M., McLaren, D.J., Spry, C.J., 1986. Toxocara canis: interaction of human blood eosinophils with the infective larvae. Exp. Parasitol. 61, 421-431.

Fialho, P.M., Corrêa, C.R., 2016. A systematic review of toxocariasis: a neglected but high-prevalence disease in Brazil. Am. J. Trop. Med. Hyg. 94, 1193-1199.

Fillaux, J., Magnaval, J.F., 2013. Laboratory diagnosis of human toxocariasis. Vet. Parasitol. 193, 327-336.

Finsterer, J., Auer, H., 2007. Neurotoxocarosis. Rev. Inst. Med. Trop. Sao Paulo 49, 279-287.

Finsterer, J., Auer, H., 2013. Parasitoses of the human central nervous system. J. Helminthol. 87, 257-270.

Fisher, M., 2003. Toxocara cati: an underestimated zoonotic agent. Trends Parasitol. 19, 167-170.

Fu, C.J., Chuang, T.W., Lin, H.S., Wu, C.H., Liu, Y.C., Langinlur, M.K., Lu, M.Y., Hsiao, W.W., Fan, C.K., 2014. Seroepidemiology of Toxocara canis infection among primary schoolchildren in the capital area of the Republic of the Marshall Islands. BMC Infect. Dis. 14, 261.

Gasser, R.B., 2006. Molecular tools — advances, opportunities and prospects. Vet. Parasitol. 136, 69-89.

Gasser, R.B., 2013. A perfect time to harness advanced molecular technologies to explore the fundamental biology of Toxocara species. Vet. Parasitol. 193, 353-364.

Gasser, R.B., Korhonen, P.K., Zhu, X.Q., Young, N.D., 2016. Harnessing the Toxocara genome to underpin toxocariasis research and new interventions. Adv. Parasitol. 91, 87-110.

Gavignet, B., Piarroux, R., Aubin, F., Millon, L., Humbert, P., 2008. Cutaneous manifestations of human toxocariasis. J. Am. Acad. Dermatol. 59, 1031-1042.

Gems, D., Maizels, R.M., 1996. An abundantly expressed mucin-like protein from Toxocara canis infective larvae: the precursor of the larval surface coat glycoproteins. Proc. Natl. Acad. Sci. USA. 93, 1665-1670.

Gibbons, L.M., Jacobs, D.E., Sani, R.A., 2001. Toxocara malaysiensis n. sp. (Nematoda: Ascaridoidea) from the domestic cat (Felis catus Linnaeus, 1758). J. Parasitol. 87, 660-665.

Gompper, M.E., 2013. The dog-human-wildlife interface: assessing the scope of the problem. In: Gompper, M.E., (Eds.), Free-Ranging Dogs and Wildlife Conservation. Oxford University Press, Oxford, p. 25. ISBN 978-0-19-181018-3.

Hayashi, E., Tuda, J., Imada, M., Akao, N., Fujita, K., 2005. The high prevalence of asymptomatic Toxocara infection among schoolchildren in Manado, Indonesia. Southeast Asian J. Trop. Med. Public Health 36, $1399-1406$.

Hewitson, J.P., Grainger, J.R., Maizels, R.M., 2009. Helminth immunoregulation: The role of parasite secreted proteins in modulating host immunity. Mol. Biochem. Parasitol. 167, 1-11.

Holland, C.V., 2015. Knowledge gaps in the epidemiology of Toxocara: the enigma remains. Parasitology 16, 114.

Horiuchi, A., Satou, T., Akao, N., Koike, K., Fujita, K., Nikaido, T., 2005. The effect of free and polyethylene glycol-liposome-entrapped albendazole on larval mobility and number in Toxocara canis infected mice. Vet. Parasitol. 129, 83-87.

Hotez, P.J., 2014. Neglected infections of poverty in the United States and their effects on the brain. JAMA Psychiatry 71, 1099-1100.

Hotez, P.J., Wilkins, P.P., 2009. Toxocariasis: America's most common neglected infection of poverty and a helminthiasis of global importance? PLoS Negl. Trop. Dis. 3, e400.

Hoy, A.M., Lundie, R.J., Ivens, A., Quintana, J.F., Nausch, N., Forster, T., Jones, F., Kabatereine, N.B., Dunne, D.W., Mutapi, F., Macdonald, A.S., Buck, A.H., 2014. Parasite-derived microRNAs in host serum as novel biomarkers of helminth infection. PLoS Negl. Trop. Dis. 8, e2701.

Hrčkova, G., Velebný, S., 2001. Treatment of Toxocara canis infections in mice with liposome-incorporated benzimidazole carbamates and immunomodulator glucan. J. Helminthol. 75, 141-146.

Hrčkova, G., Velebný, S., Obwaller, A., Auer, H., Kogan, G., 2007. Evaluation of follow-up of therapy with fenbendazole incorporated into stabilized liposomes and immunomodulator glucan in mice infected with Toxocara canis larvae. Acta Trop. 104, 122-132.

Hu, M., Chilton, N.B., Gasser, R.B., 2004. The mitochondrial genomics of parasitic nematodes of socio-economic importance: recent progress, and implications for population genetics and systematics. Adv. Parasitol. 56, $134-213$

Hu, M., Gasser, R.B., 2006. Mitochondrial genomes of parasitic nematodes-progress and perspectives. Trends Parasitol. 22, 78-84.

Hübner, J., Uhlíková, M., Leissová, M., 2001. Diagnosis of the early phase of larval toxocariasis using $\operatorname{IgG}$ avidity. Epidemiol. Mikrobiol. Imunol. 50, 67-70.

Jacobs, D.E., Zhu, X., Gasser, R.B., Chilton, N.B., 1997. PCR-based methods for identification of potentially zoonotic ascaridoid parasites of the dog, fox and cat. Acta Trop. 68, 191-200.

Jex, A.R., Waeschenbach, A., Littlewood, D.T., Hu, M., Gasser, R.B., 2008. The mitochondrial genome of Toxocara canis. PLoS Negl. Trop. Dis. 2, e273.

Jin, Y., Shen, C., Huh, S., Sohn, W.M., Choi, M.H., Hong, S.T., 2013. Serodiagnosis of toxocariasis by ELISA using crude antigen of Toxocara canis larvae. Korean J. Parasitol. 51, 433-439.

Keegan, J.D., Holland, C.V., 2010. Contamination of the hair of owned dogs with the eggs of Toxocara spp. Vet. Parasitol. 173, 161-164.

Kennedy, M.W., Maizels, R.M., Meghji, M., Young, L., Qureshi, F., Smith, H.V., 1987. Species-specific and common epitopes on the secreted and surface antigens of Toxocara cati and Toxocara canis infective larvae. Parasite Immunol. 9, 407-420.

Khademvatan, S., Abdizadeh, R., Tavalla, M., 2014. Molecular characterization of Toxocara spp. from soil of public areas in Ahvaz southwestern Iran. Acta Trop. 135, 50-54. 
Kuenzli, E., Neumayr, A., Chaney, M., Blum, J., 2016. Toxocariasis-associated cardiac diseases - a systematic review of the literature. Acta Trop. 154, 107-120.

Kuroda, E., Yoshida, Y., En Shan, B., Yamashita, U., 2001. Suppression of macrophage interleukin-12 and tumour necrosis factor-alpha production in mice infected with Toxocara canis. Parasite Immunol. 23, 305311.

Le, T.H., Anh, N.T., Nguyen, K.T., Nguyen, N.T., Thuy, do T.T., Gasser, R.B., 2016. Toxocara malaysiensis infection in domestic cats in Vietnam - An emerging zoonotic issue? Infect. Genet. Evol. 37, 94-98.

Lee, R.M., Moore, L.B., Bottazzi, M.E., Hotez, P.J., 2014. Toxocariasis in North America: a systematic review. PLoS Negl. Trop. Dis. 8, e3116.

Lee, A.C., Schantz, P.M., Kazacos, K.R., Montgomery, S.P., Bowman, D.D., 2010. Epidemiologic and zoonotic aspects of ascarid infections in dogs and cats. Trends Parasitol. 26, 155-261.

Leonardi, D., Echenique, C., Lamas, M.C., Salomon, C.J., 2009. High efficacy of albendazole-PEG 6000 in the treatment of Toxocara canis larva migrans infection. J. Antimicrob. Chemother. 64, 375-378.

Li, L., Gao, W., Yang, X., Wu, D., Bi, H., Zhang, S., Huang, M., Yao, X., 2014. Asthma and toxocariasis. Ann. Allergy Asthma Immunol. 113, 187-192.

Li, M.W., Lin, R.Q., Song, H.Q., Wu, X.Y., Zhu, X.Q., 2008. The complete mitochondrial genomes for three Toxocara species of human and animal health significance. BMC Genomics 9, 224.

Li, M.W., Zhu, X.Q., Gasser, R.B., Lin, R.Q., Sani, R.A., Lun, Z.R., Jacobs, D.E., 2006. The occurrence of Toxocara malaysiensis in cats in China, confirmed by sequence-based analyses of ribosomal DNA. Parasitol. Res. 99, 554-557.

Liu, E.W., Chastain, H.M., Shin, S.H., Wiegand, R.E., Kruszon-Moran, D., Handali, S., Jones, J.L., 2018. Seroprevalence of antibodies to Toxocara species in the United States and associated risk factors, 20112014. Clin. Infect. Dis. 66, 206-212.

Loukas, A., Hintz, M., Linder, D., Mullin, N.P., Parkinson, J., Tetteh, K.K., Maizels, R.M., 2000. A family of secreted mucins from the parasitic nematode Toxocara canis bears diverse mucin domains but shares similar flanking six-cysteine repeat motifs. J. Biol. Chem. 275, 39600-39607.

Loukas, A., Maizels, R.M., 2000. Helminth C-type lectins and host-parasite interactions. Parasitol. Today 16, 333-339.

Loukas, A., Mullin, N.P., Tetteh, K.K., Moens, L., Maizels, R.M., 1999. A novel C-type lectin secreted by a tissue-dwelling parasitic nematode. Curr. Biol. 9, 825-828.

Luna, J., Cicero, C.E., Rateau, G., Quattrocchi, G., Marin, B., Bruno, E., Dalmay, F., Druet-Cabanac, M., Nicoletti, A., Preux, P.-M., 2018. Updated evidence of the association between toxocariasis and epilepsy: systematic review and meta-analysis. PLoS Negl. Trop. Dis. 12, e0006665.

Ma, G., Holland, C.V., Wang, T., Hofmann, A., Fan, C.-K., Maizels, R.M., Hotez, P.J., Gasser, R.B., 2018. Human toxocariasis. Lancet Infect. Dis. 18, e14-e24.

Ma, G., Luo, Y., Zhu, H., Luo, Y., Korhonen, P.K., Young, N.D., Gasser, R.B., Zhou, R., 2016. MicroRNAs of Toxocara canis and their predicted functional roles. Parasit. Vectors 9, 229.

Macpherson, C.N., 2013. The epidemiology and public health importance of toxocariasis: a zoonosis of global importance. Int. J. Parasitol. 43, 999-1008.

Macuhova, K., Akao, N., Fujinami, Y., Kumagai, T., Ohta, N., 2013. Contamination, distribution and pathogenicity of Toxocara canis and T. cati eggs from sandpits in Tokyo, Japan. J. Helminthol. 87, 271276.

Magnaval, J.F., Berry, A., Fabre, R., Morassin, B., 2001. Eosinophil cationic protein as a possible marker of active human Toxocara infection. Allergy 56, 1096-1099.

Magnaval, J.F., Fabre, R., Maurières, P., Charlet, J.P., de Larrard, B., 1991. Application of the Western blotting procedure for the immunodiagnosis of human toxocariasis. Parasitol. Res. 77, 697-702.

Maizels, R.M., 2013. Toxocara canis: Molecular basis of immune recognition and evasion. Vet. Parasitol. 193, $365-374$.

Maizels, R.M., de Savigny, D., Ogilvie, B.M., 1984. Characterization of surface and excretory-secretory antigens of Toxocara canis infective larvae. Parasite Immunol. 6, 23-37.

Maizels, R.M., Tetteh, K.K., Loukas, A., 2000. Toxocara canis: genes expressed by the arrested infective larval stage of a parasitic nematode. Int. J. Parasitol. 30, 495-508.

Manini, M.P., Marchioro, A.A., Colli, C.M., Nishi, L., Falavigna-Guilherme, A.L., 2012. Association between contamination of public squares and seropositivity for Toxocara spp. in children. Vet. Parasitol. 188, 48-52.

Manzano-Román, R., Siles-Lucas, M., 2012. MicroRNAs in parasitic diseases: Potential for diagnosis and targeting. Mol. Biochem. Parasitol. 186, 81-86.

Martínez-Pulgarin, D., Munoz-Urbano, M., Gomez-Suta, L., Delgado, O., Rodriguez-Morales, A., 2015. Ocular toxocariasis: new diagnostic and therapeutic perspectives. Recent Pat. Antiinfect. Drug Discov. 10, 35-41.

Mazur-Melewska, K., Figlerowicz, M., Cwalińska, A., Mikoś, H., Jończyk-Potoczna, K., LewandowskaStachowiak, M., Służewski, W., 2016. Production of interleukins 4 and 10 in children with hepatic involvement in the course of Toxocara spp. infection. Parasite Immunol. 38, 101-107.

McSorley, H.J., Maizels, R.M., 2012. Helminth infections and host immune regulation. Clin. Microbiol. Rev. 25, 585-608.

Mendonça, L.R., Veiga, R.V., Dattoli, V.C., Figueiredo, C.A., Fiaccone, R., Santos, J., Cruz, Á.A., Rodrigues, L.C., Cooper, P.J., Pontes-de-Carvalho, L.C., Barreto, M.L., Alcantara-Neves, N.M., 2012. Toxocara seropositivity, atopy and wheezing in children living in poor neighbourhoods in urban Latin American. PLoS Negl. Trop. Dis. 6, e1886.

Mikaeili, F., Mirhendi, H., Hosseini, M., Asgari, Q., Kia, E.B., 2013. Toxocara nematodes in stray cats from Shiraz, southern Iran: intensity of infection and molecular identification of the isolates. Iran. J. Parasitol. 8, 593.

Mikaeili, F., Mirhendi, H., Mohebali, M., Hosseini, M., Sharbatkhori, M., Zarei, Z., Kia, E., 2015. Sequence variation in mitochondrial cox 1 and nadl genes of ascaridoid nematodes in cats and dogs from Iran. J. Helminthol. 89, 496-501. 
Mohamad, S., Azmi, N.C., Noordin, R., 2009. Development and evaluation of a sensitive and specific assay for diagnosis of human toxocariasis by use of three recombinant antigens (TES-26, TES-30USM, and TES120). J. Clin. Microbiol. 47, 1712-1717.

Mohammadzadeh, I., Riahi, S.M., Saber, V., Darvish, S., Amrovani, M., Arefkhah, N., Rostami, A., 2018. The relationship between Toxocara species seropositivity and allergic skin disorders: a systematic review and meta-analysis. Trans. R. Soc. Trop. Med. Hyg. 112, 529-537.

Moreira, G.M., Telmo, Pde L, Mendonça, M., Moreira, A.N., McBride, A.J., Scaini, C.J., Conceição, F.R., 2014. Human toxocariasis: current advances in diagnostics, treatment, and interventions. Trends Parasitol. 30, 456-464.

Morgan, E.R., Azam, D., Pegler, K., 2013. Quantifying sources of environmental contamination with Toxocara spp. eggs. Vet. Parasitol. 193, 390-397.

Nagy, D., Bede, O., Danka, J., SzÉnási, Z., Sipka, S., 2012. Analysis of serum cytokine levels in children with chronic cough associated with Toxocara canis infection. Parasite Immunol. 34, 581-588.

Nicoletti, A., 2013. Toxocariasis. Handb. Clin. Neurol. 114, 217-228.

Nichols, R.L., 1956. The etiology of visceral larva migrans. I. Diagnostic morphology of infective second-stage Toxocara larvae. J. Parasitol. 42, 349-362.

Nijsse, R., Mughini-Gras, L., Wagenaar, J.A., Franssen, F., Ploeger, H.W., 2015. Environmental contamination with Toxocara eggs: a quantitative approach to estimate the relative contributions of dogs, cats and foxes, and to assess the efficacy of advised interventions in dogs. Parasit. Vectors 8, 397.

Nijsse, R., Ploeger, H.W., Wagenaar, J.A., Mughini-Gras, L., 2014. Toxocara canis in household dogs: prevalence, risk factors and owners' attitude towards deworming. Parasitol. Res. 114, 561-569.

Noordin, R., Smith, H.V., Mohamad, S., Maizels, R.M., Fong, M.Y., 2005. Comparison of IgG-ELISA and IgG4ELISA for Toxocara serodiagnosis. Acta Trop. 93, 57-62.

Oguz, B., Ozdal, N., Deger, M.S., 2018. Genetic analysis of Toxocara spp. in stray cats and dogs in Van province, Eastern Turkey. J. Vet. Res. 62, 291-295.

Othman, A.A., 2012. Therapeutic battle against larval toxocariasis: are we still far behind? Acta Trop. 124, 171178.

Overgaauw, P.A., 1997. Aspects of Toxocara epidemiology: human toxocarosis. Crit. Rev. Microbiol. 23, 215231.

Overgaauw, P.A., van Knapen, F., 2013. Veterinary and public health aspects of Toxocara spp. Vet. Parasitol. 193, 398-403.

Overgaauw, P.A., van Zutphen, L., Hoek, D., Yaya, F.O., Roelfsema, J., Pinelli, E., van Knapen, F., Kortbeek, L.M., 2009. Zoonotic parasites in fecal samples and fur from dogs and cats in The Netherlands. Vet. Parasitol. 163, 115-122.

Palmer, C.S., Thompson, R.C., Traub, R.J., Rees, R., Robertson, I.D., 2008. National study of the gastrointestinal parasites of dogs and cats in Australia. Vet. Parasitol. 151, 181-190.

Pawlowski, Z., 2001. Toxocariasis in humans: clinical expression and treatment dilemma. J. Helminthol. 75, 299305.

Peixoto, P.L., Nascimento, E., Cançado, G.G., Miranda, R.R., Rocha, R.L., Araújo, R.N., Fujiwara, R.T., 2011. Identification of candidate antigens from adult stages of Toxocara canis for the serodiagnosis of human toxocariasis. Mem. Inst. Oswaldo Cruz 106, 200-206.

Pinelli, E., Roelfsema, J.H., Brandes, S., Kortbeek, T., 2013. Detection and identification of Toxocara canis DNA in bronchoalveolar lavage of infected mice using a novel real-time PCR. Vet. Parasitol. 193, 337-341.

Pivetti-Pezzi, P., 2009. Ocular toxocariasis. Int. J. Med. Sci. 6, 129-130.

Poeppl, W., Herkner, H., Tobudic, S., Faas, A., Mooseder, G., Burgmann, H., Auer, H., 2013. Exposure to Echinococcus multilocularis, Toxocara canis, and Toxocara cati in Austria: A nationwide cross-sectional seroprevalence study. Vector Borne Zoonotic Dis. 13, 798-803.

Poulsen, C.S., Skov, S., Yoshida, A., Skallerup, P., Maruyama, H., Thamsborg, S.M., Nejsum, P., 2015. Differential serodiagnostics of Toxocara canis and Toxocara cati-is it possible? Parasite Immunol. 37, 204-207.

Quintana, J.F., Makepeace, B.L., Babayan, S.A., Ivens, A., Pfarr, K.M., Blaxter, M., Debrah, A., Wanji, S., Ngangyung, H.F., Bah, G.S., Tanya, V.N., Taylor, D.W., Hoerauf, A., Buck, A.H., 2015. Extracellular Onchocerca-derived small RNAs in host nodules and blood. Parasit. Vectors 8, 58.

Roddie, G., Stafford, P., Holland, C., Wolfe, A., 2008. Contamination of dog hair with eggs of Toxocara canis. Vet. Parasitol. 152, 85-93.

Roldán, W.H., Elefant, G.R., Ferreira, A.W., 2015. Deglycosylation of Toxocara excretory-secretory antigens improves the specificity of the serodiagnosis for human toxocariasis. Parasite Immunol. 37, 557-567.

Rostami, A., Riahi, S.M., Holland, C.V., Taghipour, A., Khalili-Fomeshi, M., Fakhri, Y., Omrani, V.F., Hotez, P.J., Gasser, R.B., 2019. Seroprevalence estimates for toxocariasis in people worldwide: a systematic review and meta-analysis. PLoS Negl. Trop. Dis. (under review).

Rubinsky-Elefant, G., Hirata, C.E., Yamamoto, J.H., Ferreira, M.U., 2010. Human toxocariasis: diagnosis, worldwide seroprevalences and clinical expression of the systemic and ocular forms. Ann. Trop. Med. Parasitol. 104, 3-23.

Salem, G., Schantz, P., 1992. Toxocaral visceral larva migrans after ingestion of raw lamb liver. Clin. Infect. Dis. $15,743-744$.

de Savigny, D.H., Voller, A., Woodruff, A.W., 1979. Toxocariasis: serological diagnosis by enzyme immunoassay. J. Clin. Pathol. 32, 284-288.

Schabussova, I., Amer, H., van Die, I., Kosma, P., Maizels, R.M., 2007. O-methylated glycans from Toxocara are specific targets for antibody binding in human and animal infections. Int. J. Parasitol. 37, 97-109.

Schnieder, T., Laabs, E-M., Welz, C., 2011. Larval development of Toxocara canis in dogs. Vet. Parasitol. 175, 193-206.

Shah, S., Akbar, H., Ahmad, N., Akhtar, R., Shehzad, W., Islam, S., 2018. First report on molecular detection of toxocara species of dogs in Pakistan. J. Adv. Parasitol 5, 25-28. 
Smith, H.V., Holland, C.V., Taylor, M.R., Magnaval, J.F., Schantz, P.M., Maizels, R.M., 2009. How common is human toxocariasis? Towards standardizing our knowledge. Trends Parasitol. 25, 182-188.

Smith, H.V., Noordin, R., 2006. Diagnostic limitations and future trends in the serodiagnosis of human toxocariasis. In: Holland, C.V., Smith, H.V., (Eds); Toxocara: The Enigmatic Parasite. CABI., London, p. 89-112. ISBN: 1-84593-026-6.

Sowemimo, O.A., 2007. Prevalence and intensity of Toxocara canis (Werner, 1782) in dogs and its potential public health significance in Ile-Ife, Nigeria. J. Helminthol. 81, 433-438.

Strube, C., Heuer, L., Janecek, E., 2013. Toxocara spp. infections in paratenic hosts. Vet. Parasitol. 193, 375-389.

Suganya, G., Porteen, K., Sekar, M., Sangaran, A., 2019. Prevalence and molecular characterization of zoonotic helminths in dogs. J. Parasit. Diseases 43, 96-102.

Sultan, K., Omar, M., Desouky, A.Y., El-Seify, M.A., 2015. Molecular and phylogenetic study on Toxocara vitulorum from cattle in the mid-Delta of Egypt. J. Parasit. Dis. 39, 584-587.

Taira, K., Saeed, I., Permin, A., Kapel, C.M., 2004. Zoonotic risk of Toxocara canis infection through consumption of pig or poultry viscera. Vet. Parasitol. 121, 115-124.

Taylor, M.R., Keane, C.T., O'Connor, P., Mulvihill, E., Holland, C.V., 1988. The expanded spectrum of toxocaral disease. Lancet 1, 692-695.

Traub, R.J., Robertson, I.D., Irwin, P.J., Mencke, N., Thompson, R.C., 2005. Canine gastrointestinal parasitic zoonoses in India. Trends Parasitol. 21, 42-48.

Vidal, J.E., Sztajnbok, J., Seguro, A.C., 2003. Eosinophilic meningoencephalitis due to Toxocara canis: case report and review of the literature. Am. J. Trop. Med. Hyg. 69, 341-343.

Waap, H., Gomes, J., Nunes, T., 2014. Parasite communities in stray cat populations from Lisbon, Portugal. J. Helminthol. 88, 389-395.

Walsh, M.G., Haseeb, M.A., 2012. Reduced cognitive function in children with toxocariasis in a nationally representative sample of the United States. Int. J. Parasitol. 42, 1159-1163.

Walsh, M.G., Haseeb, M.A., 2014. Toxocariasis and lung function: relevance of a neglected infection in an urban landscape. Acta Parasitol. 59, 126-131.

Watthanakulpanich, D., Smith, H.V., Hobbs, G., Whalley, A.J., Billington, D., 2008. Application of Toxocara canis excretory-secretory antigens and IgG subclass antibodies (IgG1-4) in serodiagnostic assays of human toxocariasis. Acta Trop. 106, 90-95.

Wickramasinghe, S., Yatawara, L., Rajapakse, R.P., Agatsuma, T., 2009. Toxocara vitulorum (Ascaridida: Nematoda): mitochondrial gene content, arrangement and composition compared with other Toxocara species. Mol. Biochem. Parasitol. 166, 89-92.

Wilder, H.C., 1950. Nematode endophthalmitis. Trans. Am. Acad. Ophthalmol. Otolaryngol. 55, 99-109.

Wiśniewska-Ligier, M., Woźniakowska-Gęsicka, T., Sobolewska-Dryjańska, J., Markiewicz-Jóźwiak, A., Wieczorek, M., 2012. Analysis of the course and treatment of toxocariasis in children-a long-term observation. Parasitol. Res. 110, 2363-2371.

Won, K.Y., Kruszon-Moran, D., Schantz, P.M., Jones, J.L., 2008. National seroprevalence and risk factors for zoonotic Toxocara spp. infection. Am. J. Trop. Med. Hyg. 79, 552-557.

Yariktas, M., Demirci, M., Aynali, G., Kaya, S., Doner, F., 2007. Relationship between Toxocara seropositivity and allergic rhinitis. Am. J. Rhinol. 21, 248-250.

Yoshikawa, M., Nishiofuku, M., Moriya, K., Ouji, Y., Ishizaka, S., Kasahara, K., Mikasa, K., Hirai, T., Mizuno, Y., Ogawa, S., Nakamura, T., Maruyama, H., Akao, N., 2008. A familial case of visceral toxocariasis due to consumption of raw bovine liver. Parasitol. Int. 57, 525-529.

Zhan, B., Ajmera, R., Geiger, S.M., Gonçalves, M.T., Liu, Z., Wei, J., Wilkins, P.P., Fujiwara, R., GazzinelliGuimaraes, P.H., Bottazzi, M.E., Hotez, P., 2015. Identification of immunodominant antigens for the laboratory diagnosis of toxocariasis. Trop. Med. Int. Health 20, 1787-1796.

Zhu, X.Q., Gasser, R.B., Chilton, N.B., Jacobs, D.E., 2001. Molecular approaches for studying ascaridoid nematodes with zoonotic potential, with an emphasis on Toxocara species. J. Helminthol. 75, 101-108.

Zhu, X.Q., Jacobs, D.E., Chilton, N.B., Sani, R.A., Cheng, N.A., Gasser, R.B., 1998. Molecular characterization of a Toxocara variant from cats in Kuala Lumpur, Malaysia. Parasitology 117, 155-164.

Zhu, X.Q., Korhonen, P.K., Cai, H., Young, N.D., Nejsum, P., von Samson-Himmelstjerna, G., Boag, P.R., Tan, P., Li, Q., Min, J., Yang, Y., Wang, X., Fang, X., Hall, R.S., Hofmann, A., Sternberg, P.W., Jex, A.R., Gasser, R.B., 2015. Genetic blueprint of the zoonotic pathogen Toxocara canis. Nat. Commun. 6, 6145.

Zibaei, M., Sadjjadi, S., Maraghi, S., 2017. The occurrence of Toxocara species in naturally infected broiler chickens revealed by molecular approaches. J. Helminthol. 91, 633-636. 


\section{FIGURES AND TABLES}

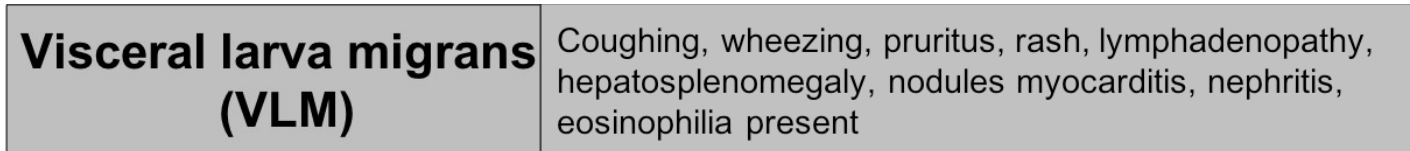

\begin{tabular}{|c|l|}
\hline $\begin{array}{c}\text { Ocular larva migrans } \\
\text { (OLM) }\end{array}$ & $\begin{array}{l}\text { Chronic endophthalmitis, retinitis, posterior/peripheral } \\
\text { granulomata, Uni-ocular visual impairment, blindness }\end{array}$ \\
\hline
\end{tabular}

\begin{tabular}{|c|l|}
\hline $\begin{array}{c}\text { Neurotoxocariasis } \\
\text { (NT) }\end{array}$ & $\begin{array}{l}\text { Fever, headache, meningitis, encephalitis, cerebral } \\
\text { vasculitis, myelitis, epilepsy, neurodegenerative } \\
\text { disease, cognitive and developmental delays }\end{array}$ \\
\hline
\end{tabular}

Covert toxocariasis (CT) delays accompanied with eosinophilia and elevated IgE

Fig. 1. The range of clinical syndromes associated with human toxocariasis. 


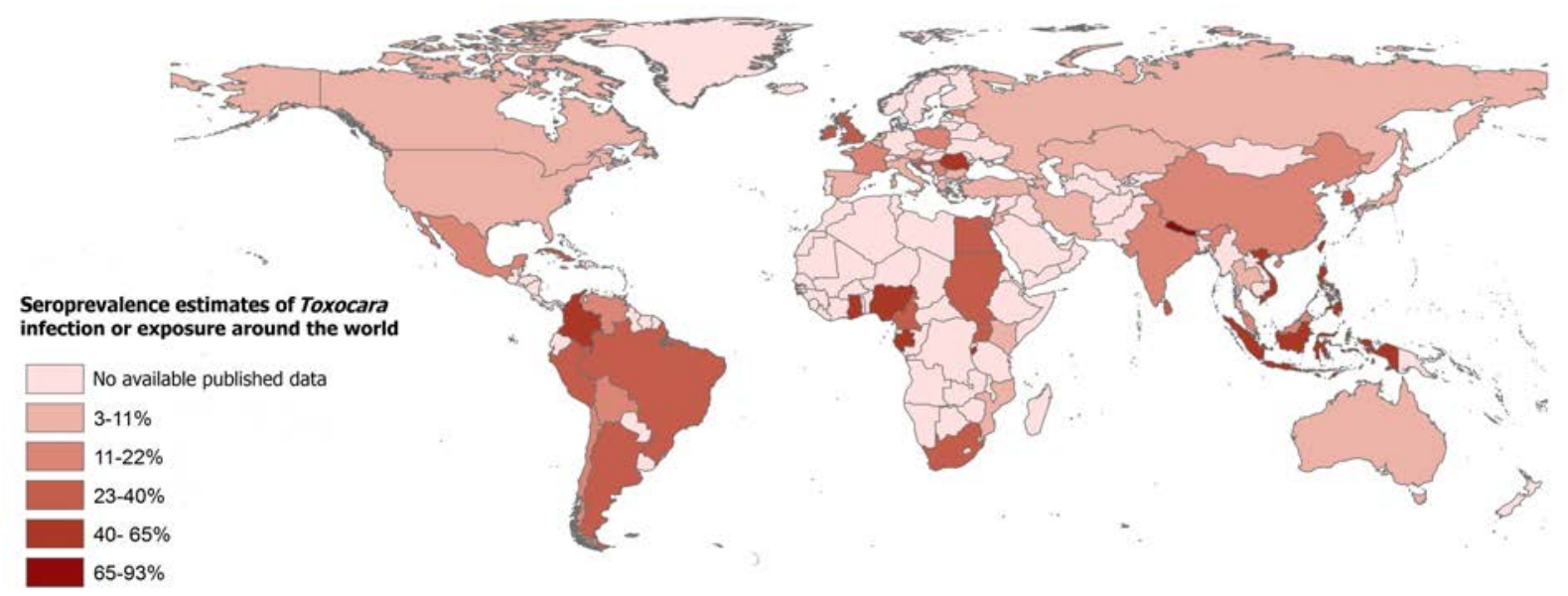

Fig. 2. Estimated seroprevalences of Toxocara infection or exposure around the world. Prevalence values (\%) are estimated from published works (for details refer to Appendix Table 1). 


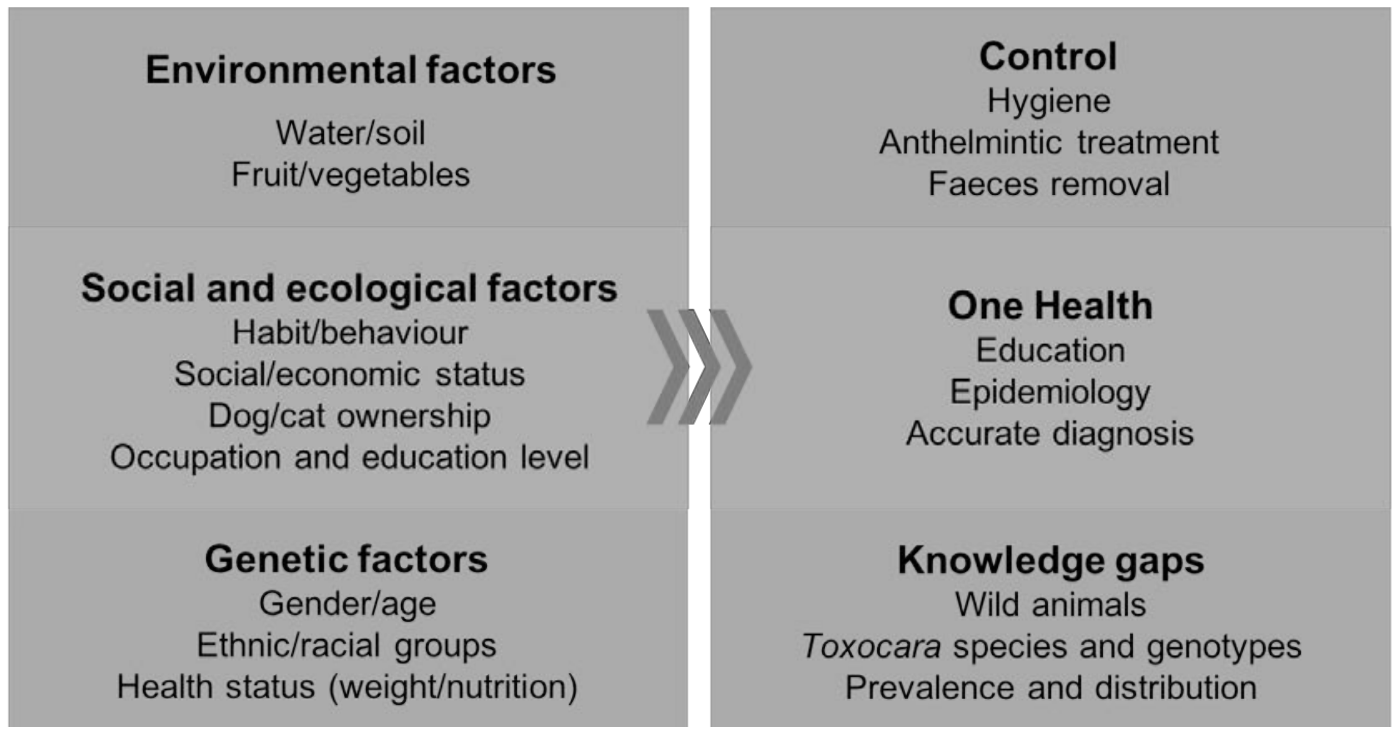

Fig. 3. Epidemiological risk factors and determinants of human toxocariasis. Human toxocariasis can be influenced by numerous factors including contamination of the environment by Toxocara eggs, social/ecological aspects (animal ownership, education and/or occupation) and genetic factors (e.g., age, gender and/or health status). A One Health strategy should improve our knowledge base and enhance the prevention and control of toxocariasis. 
Table 1. Key serological/immunological methods in current use for the detection of Toxocara infection(s) or exposure, and/or the diagnosis of toxocariasis, and brief description of purpose and performance.

\begin{tabular}{lll}
\hline Methodology & Purpose and performance & References \\
\hline IgG-TCLA-ELISA & $\begin{array}{l}\text { Detects specific total IgG in human serum; 92\% sensitivity; } \\
87 \% \text { specificity }\end{array}$ & Jin et al. (2013) \\
IgG-TES-WB & $\begin{array}{l}\text { Detects specific total IgG in human serum; "high” } \\
\text { specificity; "minor" cross-activity }\end{array}$ & $\begin{array}{l}\text { Magnaval et al. (1991) } \\
\text { Noordin et al. (2005) }\end{array}$ \\
IgG-TES-ELISA & $\begin{array}{l}\text { Detects specific total IgG/IgG subclass in human serum; 60- } \\
98 \% \text { sensitivity; 36-81\% specificity }\end{array}$ & $\begin{array}{l}\text { Watthanakulpanich et al. } \\
\text { (2008) } \\
\text { Peixoto et al. (2011) }\end{array}$ \\
IgG-dTES-WB & $\begin{array}{l}\text { Detects specific total IgG in human serum; no cross- } \\
\text { reactivity with 32, 55 and 70 kDa fractions of dTES }\end{array}$ & Roldán et al. (2015) \\
IgG-dTES-ELISA & $\begin{array}{l}\text { Detects specific total IgG in human serum; 100\% sensitivity } \\
\text { and specificity }\end{array}$ & Roldán et al. (2015) \\
IgG4-rTES-ELISA & $\begin{array}{l}\text { Detects specific IgG4 subclass in human serum; 93\% } \\
\text { sensitivity and "increased" specificity } \\
\text { Detects specific total IgG in human serum; 92\% sensitivity; } \\
\text { IgG-DiM-BSA-ELISA }\end{array}$ & Mohamad et al. (2009) \\
\hline
\end{tabular}

Footnote: IgG: immunoglobulin G; TCLA: crude antigens from T. canis larvae; ELISA: enzyme-linked immunosorbent assay; TES: Toxocara canis excretory/secretory antigens; WB: Western blot; dTES: deglycosylated TES antigens; rTES: recombinant TES antigens; DiM-BSA: di-O-methylated coupled bovine serum albumin

Table 2. List of studies reporting the molecular identification of Toxocara species in different host species and in soil

\begin{tabular}{|c|c|c|c|c|c|c|}
\hline \multirow{2}{*}{ Country } & \multirow{2}{*}{$\begin{array}{l}\text { Origin } \\
\text { of sample }\end{array}$} & \multirow{2}{*}{$\begin{array}{l}\text { Number of } \\
\text { samples tested } \\
\text { by molecular } \\
\text { means }\end{array}$} & \multicolumn{3}{|c|}{ Toxocara spp. } & \multirow{2}{*}{ References } \\
\hline & & & T. canis & T. cati & T. malaysiensis & \\
\hline Switzerland & Dog & 35 & 24 & 11 & - & Fahrion et al. (2011) \\
\hline Iran & Dog & 28 & 9 & - & - & Mikaeili et al. (2015) \\
\hline Vietnam & Dog & 14 & 14 & - & - & Le et al. (2016) \\
\hline Turkey & Cat and Dog & 20 & 17 & 3 & - & Oguz et al. (2018) \\
\hline Pakistan & Dog & $26^{a}$ & - & - & - & Shah et al. (2018) \\
\hline India & Dog & $30^{\mathrm{a}}$ & 25 & & - & Suganya et al. (2019) \\
\hline Switzerland & Cat & 36 & - & 36 & - & Fahrion et al. (2011) \\
\hline Iran & Cat & 6 & - & 6 & - & Mikaeili et al. (2013) \\
\hline Iran & Cat & 32 & - & 32 & - & Mikaeili et al. (2015) \\
\hline Vietnam & Cat & 15 & - & - & 15 & Le et al. (2016) \\
\hline Iran & Chicken & 6 & 5 & 1 & - & Zibaei et al. (2017) \\
\hline Japan & Soil & $102^{\mathrm{a}}$ & - & 66 & - & Macuhova et al. (2013) \\
\hline Iran & Soil & 71 & 12 & 59 & - & Khademvatan et al. (2014) \\
\hline Iran & Soil & 24 & 1 & 23 & - & Choobineh et al. (2018) \\
\hline
\end{tabular}

a samples that amplified by PCR. 